\title{
Possibilities and potentials in teaching writing ${ }^{1}$
}

\author{
István Jánk - Szilvia Rási
}

\begin{abstract}
Nowadays, teaching writing belongs to the most current scientific fields. There are many aspects that can be examined related this topic. In this paper we deal with the main questions of teaching writing. At first hand, we discuss the concept and difficulties of writing, the general principles for teaching writing and the correction of written works. On the other hand, concrete activities are presented based on the theoretical part, more precisely on the stages of the writing process.
\end{abstract}

Keywords: writing; teaching writing; stages of writing; writing activities

Subject-Affiliation in New CEEOL: Social Sciences - Education - School Education

DOI: 10.36007/eruedu.2020.2.023-033

\section{Introduction}

In this paper we deal with some fields connected to writing in language teaching. The reason of choosing this topic is because most people regard speaking more important than writing. Teaching writing is not as easy as it may seem. The work consists of two main parts. First, we give a brief theoretical background on the chosen topic. The second main section of the work is the practical part where activities of teaching writing are presented based on the main stages of writing.

In the first chapter we discuss the concept of writing based on several authors. The next chapter deals with teaching writing where general principles for teaching writing and stages of writing are discussed. The third chapter of the work focuses on the correction of written works. In the practical part we present and describe activities based on three main stages of writing, namely: pre-writing stage, drafting stage, finally revising and editing stage.

\section{The concept of writing}

Language educators, experts and researchers have been using the concepts of four basic language skills (also known as "macro-skills") for a long time. These skills are listening, speaking, reading and writing. These four basic skills are strongly related to each other by two aspects. The first is the mode of communication, which means oral or written mode. The second one is the direction of communication: receiving or producing the message. Listening comprehension is the receptive skill,

1 * The study was supported by the Visegrad Scholarship Program (\#51910106) 
while speaking is the productive skill in the oral mode. Reading is the receptive skill, while writing is the productive skill in the written mode. It often seems to be the hardest of all the skills (even for native speakers of a language), because it includes not just a graphic representation of speech but also the development and presentation of thoughts (Aydoğan 2014).

There are several kinds of writing. For example, on a personal level we can write informal letters, letters to friends, messages and some of us keep diaries. Most of us sometimes have to fill in forms or applications, questionnaires. Occasionally we write formal letters, so the writing we do generally relates to our professional life. But for most of us writing is an occasional activity. On the other hand, some people write spontaneously and for pleasure. They spend much time writing poetry or fiction, short stories, lists (e.g. 'to do' lists, shopping lists), emails, notes, memos, postcards, posts and so on. People use writing for a variety of reasons, for example to entertain, to keep a record, to ask questions, to organize their thoughts, to pass on information, as part of an assessment process, to share opinions, etc. (Byrne 1993: 2; Lindsay and Knight 2006: 85).

Of course, writing is not only difficult in foreign or second languages but also in one's mother tongue. We can divide the problems of writing into three parts: psychological difficulty, linguistic difficulty and cognitive difficulty. First, the writer has to decide what information the reader needs and how best to express this information to the reader. Therefore, there is a psychological difficulty, because the writer cannot consult the reader, there is no audience and no reaction (except in some cases of online/virtual space, e.g. chat, social workplace). Second, there is the linguistic difficulty, which means that there is a difference between the written language and the language used in speech. Speech is spontaneous, we have very little time to pay attention to organizing our sentence structures. We repeat, backtrack, expand depending on how people react to what we say. Written language is more formal, we use learned conventions and rules. We have to pay attention to our choice of sentence structure and to the way these sentences are linked together. Finally, there is the problem of cognitive difficulty. Students have to organize their thoughts on paper for unknown readers, but when we speak, we do it without conscious effort or thought and we talk just because we want. Byrne (1993:5) states that "writing is learned through a process of instruction: we have to master the written form of the language and to learn certain structures which are less used in speech or perhaps not used at all, but which are important for effective communication in writing".

Writing can be defined in many ways. In the following we provide some definitions formulated by experts. We do not strive for completeness, we only mention the most relevant and most influential theories and definitions. In Charles and Jill Hadfield's opinion, writing is an artificial activity in a way that speech is not. Writing is learned, while speaking is acquired as a part of growing up (Hadfield 1990), while Bowker claims that writing is a skill which is required in many contexts throughout the whole life (Bowker 2007: 2). Byrne (1993: 1) states that "when we write, we use graphic symbols: that is, letters or combinations of letters which relate to the sounds we make when we speak." According to some specific con- 
ventions from the symbols we form words, and words are the building blocks of the sentences. Then for the text people produce a sequence of sentences arranged in a particular order and linked together in certain ways (Byrne 1993: 1-7). Cora Lindsay and Paul Knight (2006) have the same opinion when they say that the process of writing is very similar to speaking except that we do it with letters and not with sounds. Moreover, they think that writing is also one part of the process of language learning. They say that people write to practice the language; to reinforce the language they have learnt; to help memorization; as a way of recording language; as part of being assessed.

To Liz Hamp-Lyons and Ben Heasley's (2006: 13) mind, "writing is clearly a complex process, and competent writing is frequently accepted as being the last language skill to be acquired (for native speakers of the language as well as for those learning a foreign/second language)". They also say that only a low number of people write spontaneously and feel comfortable with a formal writing task, because when someone else (for example a teacher) asseses their written product, they feel uncomfortable (Lyons - Heasley 2006: 13). Bárdos (2000: 178) claims that writing skill is a learned language skill in which signs formed in accordance with conventions specific to a given language are continuously and automatically recorded, while recognizing the interplay between phonetic combinations and spelling, which, on the one hand, require abstraction and, on the other hand, represent the randomness of this relationship according to the traditions of the given language.

From these definitions above, we can summarize that writing is a process which is made up from a series of steps, in which the thoughts of people are arranged into symbols which create words, phrases, sentences and texts.

\section{Teaching writing}

We have to make a distinction between writing in one's mother tongue and writing in a foreign language. The most important differences are particularly in the learning situation. Most children learn to write in their mother tongue at school, at the age of six or seven. By this time their communication skill is developed, therefore, they also have to develop their writing skills. They do not use it only at English lessons, but also on the lessons of history, geography, etc. (Byrne 1993: 5).

Ann Raimes (1983: 3) states that writing in a foreign language helps students learn grammatical structures, idioms, vocabulary and it can help students to "discover a real need for finding the right word and the right sentence". Writing in a foreign language is quite difficult because writers have to deal with many things when they produce a piece of writing, e.g. syntax (sentence structure, sentence boundaries, stylistic choices, etc.); content (relevance, clarity, originality, logic, etc.); the writer's process (getting ideas, getting started, writing drafts, revising); the reader/s; the reason for writing; word choice (vocabulary, idiom, tone); organization (paragraphs, topic and support, cohesion and unity); mechanics (handwriting, spelling, punctuation, etc.); grammar (rules for verbs, agreement, articles, pronouns, etc). 
According to Gadušová and Hartanská (1994), language structures and vocabulary are not learnt by memorization, pattern drilling and mimicry, but rather by using linguistic forms because they are required in specific settings. This is a special classroom setting, where students can perform tasks - where they discover certain language forms. According to them, the purpose of writing is also very important because learners have to see why they are doing things at the lessons. Therefore, the task must be clear for them every time. In their book titled Methodology of teaching English as a foreign language, the authors (Gadušová-Hartanská 1994: 63) specify four characteristics for the tasks: 1. product as a result (product must be put in the context); 2. specific audience (towards which the product is directed: the audience may be the speaker himself, a friend, a teacher, a mother, etc.); 3. function (it may be cognitive, affective or both); 4. linguistic focus (themes that help teachers to create new tasks).

Raimes (1987: 3) states that teaching writing nowadays focuses much more on the process of writing. The author claims that teaching writing is important because writing helps students learn in several ways at the same time. On the one hand, writing reinforces the grammatical structures, idioms and vocabulary that we have been teaching our students. Second, when our students write, they also have a chance to be adventurous with the language, to go beyond what they have just learned to say, to take risks. When learners write, they necessarily become very involved with the new language; the effort to express ideas and the constant use of eye, hand and brain is a unique way to reinforce learning.

In addition, Byrne (1993: 6-7) states that in the early stages of a course, writing serves a variety of pedagogical purposes. In particular, they claim that

- to introduce and practice different forms, we have to use different learning styles and needs;

- written works give us evidence that students are making progress in the language;

- a foreign language has to be demonstrated by exposure to more than one medium, because it is more effective when we use several different activities and opportunities;

- writing provides a variety of activities in the classroom (as a break from oral work);

- writing is often used in formal and informal testing.

In the intermediate stages of language learning, the above-mentioned pedagogical factors are at play and in addition, we can provide a more extensive scale and integrate it more effectively with other skills. The written language itself has to provide contexts for learning and writing activities may be related to these. At both intermediate and post-intermediate levels, writing could become a goal in itself (Byrne 1993: 7). We have to concentrate on forms of writing which have a practical value, which students may use in practice, in their everyday life.

It is often emphasized that writing is a process in which the individuals are working alone. In contrast, it can be seen nowadays that there is a growing interest among teachers and researchers in collaborative writing (Storch, 2018) which means that the production of a single text involves two or more writers. This turn 
has two main reasons. First, the workplace has a huge effect on writing. Studies have shown (Mirel-Spilka, 2002) that writing appears often as a team work rather as an individual work in a number of workplaces. Second, the appearance of Web 2.0 applications (Google Docs, blogs, the Wikipedia) also contributed to the trend. These services have transformed literacy practices, people can now create and share text easier than before (Vandergriff, 2016). In foreign language teaching, there is also growing interest in collaborative writing (Swain, 1998). New techniques have appeared such as the dictogloss, in which learners have to cooperate to create the final version of the written text.

\subsection{General principles for teaching writing and stages in writing}

Lindsay and Knight (2006: 87) stated that learners need to develop the following skills in the process of teaching/learning writing:

- handwriting: forming letters, connected scripts, upper and lower case;

- spelling;

- use of punctuation;

- forming sentences: word order, endings, relationships;

- writing longer texts: coherence and cohesion;

- using the appropriate layout;

- using the appropriate level of formality;

- study skills: making notes, keeping records, etc.

Byrne divides the principles of teaching writing into four main categories, namely: focus on accuracy, focus on fluency, focus on text, focus on purpose. Focus on accuracy means that in written work we can recognize mistakes because students write what they want. On the other hand, accuracy-oriented approaches stressed the importance of control. Students have to think about how to write and combine each sentence type and structure. Manipulation exercises are used to give students the experience of writing connected sentences. This controlled-to-free approach emphasizes step-by-step learning and formal correctness. The category of focus on fluency led students to write as much as possible and as quickly as possible without worrying about making mistakes. In this way students write what they want to write and in this case writing is an enjoyable experience for them. The third category, the focus on text focuses the constructing and organizing paragraphs. It uses techniques such as: forming paragraphs from jumbled sentences, writing parallel paragraphs, developing paragraphs from topic sentences. The last category, focus on purpose, is very intresting and important for teaching. In the real life we have a reason for writing and we write for somebody. These factors have often been neglected in teaching writing. This approach motivates students to write and shows them that writing is a form of communication (Byrne 1993: 21-23).

As mentioned above, for writing students need to develop mainly the following skills: handwriting, spelling, use of punctuation, forming sentences, using the appropriate level of formality, being able to make notes, keep records (Lindsay and Knight 2006: 87). According to Gadušová and Hart'anská (1994: 63), there are certain aspects of written language that students need to know. 
These aspects are the following:

a) knowledge of the (English) alphabet;

b) knowledge of the phoneme-grapheme correspondences in English;

c) knowledge of possible sentence structures in English;

d) knowledge of the structure of short discourses, such as friendly letters, advertisements, etc.;

e) knowledge of the structure of more formal short discourse types, such as business letters;

f) knowledge of the structure of paragraph types in English;

g) knowledge of the form of a formal essay;

h) knowledge of formal writing genres, such as the short story, etc.

i) Byrne (1993:27-29) set out the issues below, which can be used as a guideline for a writing program:

j) teach the learners how to write: writing skills require special teaching;

k) teach the learners how to write texts;

I) teach the learners how to write different kinds of texts;

$\mathrm{m}$ ) provide adequate and relevant experience of the written language;

n) show the learners how the written language functions as a system of communication;

o) make writing tasks realistic and relevant;

p) integrate writing with other skills;

q) use a variety of techniques and practice formats;

r) provide appropriate support;

s) be sympathetic.

Beyond the general principles of teaching writing, we should also mention the steps of writing. Langan (2001: 23) suggests that for many people writing is a process which involves the following steps. The first one is discovering a thesis often through prewriting. The second is developing solid support for the thesis, often through more prewriting. The following step is organizing the thesis and supporting material and writing it out in a first draft. The last one is revising and then editing carefully to ensure an effective, error-free paper.

Moreover, Langan (2001: 23-36) distinguishes between several stages of writing, namely: prewriting, writing the first draft, revising and editing. In the prewriting stage, the writer has to think about the topic and develop it. Langan lists five techniques for the prewriting stage: questioning, diagramming, making a list, preparing a scratch outline and free writing. The second stage is writing the first draft, where the writer may add some additional thoughts which are not written down in the prewriting process. In the revising stage, the writer re-writes the paper. The writer can add some thoughts and clarify it. The last stage is editing. Here the writer re-reads the text and corrects errors in grammar, punctuation and spelling.

In their book titled Study Writing, Lyons and Heasley note that "writing is commonly seen as a three-stage process: pre-writing, writing and rewriting" (Lyons - Heasley, 2006:13). They state that the teacher has to help students master the process of writing by participating in it with them, and not criticizing the product. 
Lindsay and Knight divide the process of writing also into three stages which are the following. The first is the pre-writing stage when the writer has to think about the reader, brainstorm, gather information, practice particular language forms, practice specific writing skills, decide on the content, look at a model text, write an outline or plan. The next is the writing stage: learners write a draft, edit it and rewrite it until they complete the final version. The last one is the post-writing stage. In this stage learners share their finished work, and comment on each other's writings (Lindsay-Knight 2006: 95).

\section{Correcting written works}

Correcting students' language errors (e.g. in written works) has always received excessive attention. Correcting learners' errors is relevant in three different aspect. First of all, they tell the teacher about the progress of the learner: how the learning process goes on, what remains to be learnt, what makes it difficult, etc. Second, they indicate how a language is acquired and what strategies the learner practices in the process of learning. Finally, they can be regarded as a tool the learner uses in order to learn. Although errors are seen as systematic deviations made by language learners who have not yet mastered the rules, norms of L2, but a learner cannot self-correct those errors because they are a reflective product of his current stage of the language learning process (Amara 2018; Corder 1967).

Jeremy Harmer (1991) states that the correction of written work could have the same basis as the correction of oral work. This means that sometimes the teacher pays more attention to accuracy, and sometimes to content. The correction of written works can be done by both the students and the teacher. The teacher can use a variety of symbols which help students understand their mistakes. The teacher needs separate symbols for spelling, wrong verb tense, lack of concord, wrong word order, inappropriate language, punctuation, a missing word, unclear meaning, etc. For example: $\mathrm{WO}=$ word order, $\mathrm{SP}=$ spelling, $\mathrm{P}=$ punctuation, $\mathrm{T}$ =tense, etc. It is very important to note that the teacher has to use always the same symbol for the same mistake (Harmer 1991: 146-147).

Several versions of the correction procedure are known (Byrne 1993):

- correct all the mistakes - it is very time-consuming for the teacher and it can have a negative effect on students if they get their work back covered with red ink (the so called "red-pen-syndrome");

- correct mistakes selectively - you correct only certain areas; such as tenses or articles;

- indicate mistakes so that the students can correct them - it is done by underlining the mistakes and using some kind of symbol which draws the students ' attention to the mistake they have made;

- let the students identify and correct their own mistakes

There are some other things we can do to help our students when they make mistakes, for example explain a mistake; remind students that they should consult with somebody about a mistake and/or using mistakes as a basis for remedial teaching. 


\section{Practical part}

This section of our paper introduces some practices or activities releated to writing. The activities are grouped by the above-mentioned stages of writing: pre-writing, drafting, revising and editing. The activities also demonstrate some potential solutions.

\subsection{Pre-writing stage activities}

Name of the activity: Imaginary friend

Aids: whiteboard, pen

Objectives: Ss are able to make a description about someone.

Procedure: The teacher says to the students: "Imagine that you have a really good friend who is always next to you". The teacher asks students to go to the whiteboard one by one, and every student will draw a detail about their friend on the board. They also have to say what their friend has, what they are drawing, using the structure "he/she has". For example: "he/she has a curly hair". At the end of this activity, students have to give a name for that creature on the board.

\section{Name of the activity: A Head for Words}

Aids: none

Objectives: to be able to collect words connected to a specific topic.

Procedure: The first person says one word connected to one specific topic, e.g. Holidays. The next person says the previous word and adds another word (still the same topic); the third person says the first and second words and adds a third word; the fourth person repeats the first three words and adds a fourth word. The game continues until someone forgets one of the words in the string. Of course, one person needs to be the recorder who keeps track of the words and stops the game when a word is forgotten.

\section{Name of the activity: Spelling backward}

Aids: paper, pen

Procedure: The teacher starts to spell words backwards. Students have to write down letter by letter what the teacher dictates them. The teacher does not tell the students where are the spaces between the words. Then students divide the words alone, and read them aloud.

\subsection{Drafting stage activities}

Name of the activity: Timeline

Aids: Prezi or Timeline maker (software)

Procedure: Students have to make a story on a given topic. They can use pictures, data, videos, songs, etc. Then they have to introduce every presentation to the others. 
Name of the activity: To the right column

Aids: exercise (see below)

Procedure: Students have to complete the table with the given words. Then they have to find four more adjectives which describe positive characteristics and add them to the table.

Exercise: Complete the table with the words below. Then find four more adjectives which describe positive characteristics. Add them to the table.

strong, hardworking, lazy, successful, untidy, argumentative, ambitious, sociable, confident, thoughtful, talkative, bossy, self-centered, indecisive, organized, dynamic, selfish, brave, dishonest, friendly, reliable, sneaky, afraid, willing, arrogant, helpful, impolite, jealous, dynamic, loyal, obedient

\begin{tabular}{|l|l|}
\hline Positive characteristics & Negative characteristics \\
\hline & \\
& \\
\hline
\end{tabular}

Name of the activity: Invent a title

Aids: paper, pen, nonfigurative and abstract pictures (eg. DIXIT cards)

Procedure: Every student chooses an abstract/nonfigurative picture and has to invent a title for it, then they have to write it at the top of the paper. After that everybody introduces their pictures with the titles they have created.
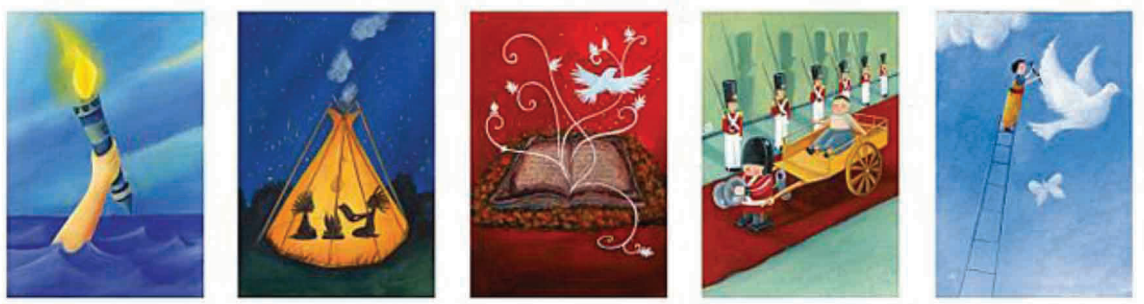

Name of the activity: Choose a person

Aids: paper, pen

Procedure: Students have to think about a person they admire. Then they have to write a description about that person using the Phrases2know list. 


\subsection{Revising and editing stage activities}

\section{Name of the activity: Postcard}

Aids: postcards

Procedure: The teacher distributes postcards with a landscape on them. Then asks students to look at the picture on the postcard and imagine that this is something they saw whilst on their holiday. After that the teacher asks students to write a postcard to a friend telling them about their imaginary holiday. Once they have written the cards, they have to exchange them with someone else. Then students have to read the postcards they have received and write a response to them.

\section{Name of the activity: Correct the facts}

Aids: picture and sentences on a sheet of paper

Procedure: There are false sentences next to a picture. Students have to re-write the sentences so that they match the picture.

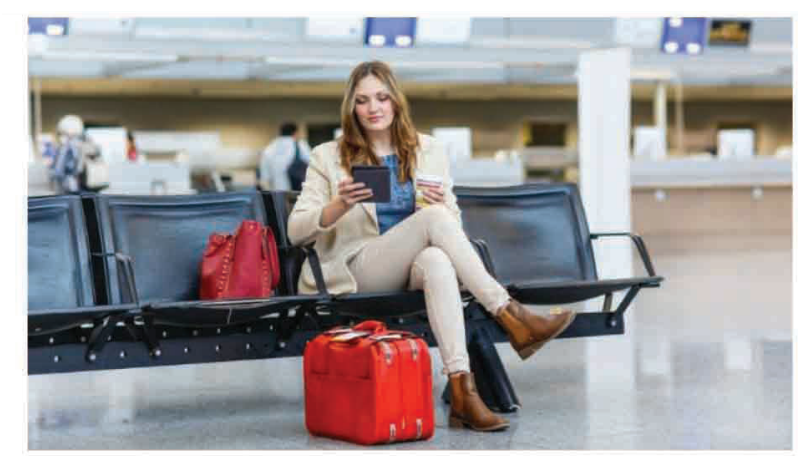

Text: At the airport, I saw an old woman sitting on a chair. She was talking to her husband. Next to them was a green luggage, which was placed on the chair. Re-write the previous text:

Name of the activity: Correct the mistakes in the text

Aids: text

Procedure: Students get a text which is full of mistakes. They have to correct it. 


\section{References}

Amara, Naimi (2018): Correcting Students' Errors: Theory and Practice. Current Educational Research 1 (5): 45-57.

Aydoğan, Hakan (2014): The Four Basic Language Skills, Whole Language \& Intergrated Skill Approach in Mainstream University Classrooms in Turkey. Mediterranean Journal of Social Sciences 5:9.

Bárdos, Jenö (2000): Az idegen nyelvek tanításának elméleti alapjai és gyakorlata. Budapest: Nemzeti Tanönyvkiadó.

Bowker, Natilene (2007): Academic Writing:A Guide to Tertiary Level Writing. Massey University.

Byrne, Donn (1993): Teaching Writing Skills. London: Longman.

Corder, S. P. (1967): The Significance of Learners' Errors. International Review of Applied Linguistics in Language Teaching 5 (4): 161-170.

Gadušová, Zdenka - Hartanská, Jana (1994): Methodology of Teaching English as a Foreign Language. Nitra: Vysoká Škola Pedagogická.

Hadfield, Jill - Hadfield, Charles (1990): Simple writing activities. Oxford University Press. Hamp-Lyons, Liz - Heasley, Ben (2006): Study Writing. Cambridge University Press.

Harmer, Jeremy (1991): The Practice of English Language Teaching. London: Longman.

Langan, John (2001): College Writing Skills With Readings. McGraw-Hill Higher Education.

Lindsay, Cora - Knight, Paul (2006): Learning and Teaching English. A course for teachers. Oxford University Press.

Mirel, Barbara -Spilka, Rachel (eds.) (2002): Reshaping technical communication: New directions and challenges for the 21st century. Mahwah, $\mathrm{NJ}$ : Lawrence Erlbaum.

Storch, Neomy (2018): Collaborative Writing. Language Teching. 52/1. pp. 40-59.

Raimes, Ann (1983): Techniques in Teaching Writing. Oxford University Press.

Swain, Merrill (1998): Focus on form through conscious reflection. In C. Doughty \& J. Williams (eds.), Focus on form in classroom second language acquisition. Cambridge: Cambridge University Press, 64-81.

Vandergriff, llona (2016): Second-language discourse in the digital world: Linguistic and social practices in and beyond the networked classroom. Amsterdam: John Benjamins. 